\title{
Proposal for a unified CCN nomenclature
}

The variety of names and biological functions that have been attributed to the CCN proteins have led several researchers in the field to propose a nomenclature unification.

Further to the nomenclature meeting held during the first international workshop on the CCN family of genes in Saint-Malo, a consensus has been reached in favour of keeping the CCN acronym.

It is now proposed to designate the members of the CCN family with a number attached to the CCN acronym, the number reflecting the chronology of their discovery. Some genes have been assigned different names in different species (for example, ctgf in human and fisp12 in mouse; cyr61 in mouse and CEF10 in chicken). It is recommended that a single name should be used throughout the different species. For example, CCN1 would represent cyr61 in all species, with a lower case letter in front of the name to identify species if needed (human CCN1 (hCCN1), mouse CCN1 (mCCN1), etc). According to this proposal cyr61 will be designated CCN1, ctgf will become CCN2, nov will be CCN3, and WISP-1-3 will be CCN4-6.
During a transition period, it might be helpful for readers and authors to quote in brackets the initial name of the CCN gene-for example, hCCN1 (cyr61), bearing in mind that the eventual official name would be CCN1.

The steering committee of the CCN society (see below) will be acting as a nomenclature committee for the attribution of CCN names to new member genes of the CCN family yet to be discovered.
Steering committee of the CCN Society
B Perbal, president
$\mathrm{H}$ Yeger, vice president
L Lau, treasurer
C Ayer, vice treasurer
D Brigstock, scientific secretary
A Perbal, administrative secretary
G Grotendorst
D Pennica
P Schofield
ccnsociety@mageos.com
http://www.ccnsociety.jussieu.fr

See which articles have just been accepted for publication and preview the table of contents for the next issue a month before it is published

\section{www.jclinpath.com}

